\section{Power from the sun}

Pierre Langereux of La Recherche reports from France following an international symposium on solar electricity held last month in Toulouse

"BEFORE solar energy becomes a major energy source for the 21 st century, its development will require financial expenditure of the same order of magnitude as that needed for the development of nuclear energy." So said the scientific director of the National Scientific Research Centre (CNRS), which, together with the National Space $\mathrm{Re}$ search Centre (CNES), organised the first international colloquium on solar electricity. He was speaking at the end of the meeting, which was attended by about 300 scientists from over 30 countries and produced an agreement on scientific and technical collaboration in developing solar energy through photovoltaic and thermodynamic conversion.

Photovoltaic conversion, perfected 20 years ago by Bell Laboratories and in general use since then to feed manmade satellites, is based on the capacity of certain semi-conductors (silicon, cadmium suphide, cadmium telluride, gallium arsenide) to transform light energy directly into electricity. Photopiles were developed for use in space exploration, where cost is of comparatively little importance, but they are still much too expensive to be widely used on earth. Silicon photopiles-the only ones currently in commercial use -have been used on earth for about fifteen years already, but for a few limited and highly specialised uses only.
In spite of the promising beginnings, there is still much to be done to make solar energy competitive with the other energy sources already in use. World production of photopiles for terrestrial application is currently equivalent to about $150 \mathrm{KW}$ per year $-100 \mathrm{KW}$ in the USA, $30 \mathrm{KW}$ in France, and the rest in Japan and Germany. But the market is expanding. In 1980 the production of silicon photopiles is expected to be of the order of about $10 \mathrm{MW}$ : the price per watt of solar cells (currently \$21) may have been reduced by then to $\$ 5$ or $\$ 10$ through improvements in the manufacturing process, while in ten years the price could have fallen by a factor of 100 if current research on silicon cells in thin layers bears fruit. The most interesting prospects, however, seem to lie in the development of photopiles using other materials such as cadmium sulphide and cadmium telluride, which were prematurely abandoned for space projects several years ago.

What of thermodynamic conversion? This uses solar ray collectors to heat water which, when transformed into steam, activates an alternator or turbine after passing through a heat exchanger. To reach high power levels, solar towers are needed; heliostats receive solar rays and concentrate them onto a steam generator placed at the top of a concrete tower. The higher the tower, the greater is the capacity of the power station.

Thermodynamic power stations have evolved rapidly, especially in France, and the Sofretes company has recently installed the first solar thermodynamic power station at La Pas (Mexico). Other projects will follow, with more powerful experimental power stationsone of $1 \mathrm{MW}$ at Odeillo (France), for example, and another of $5 \mathrm{MW}$ in the USA. Both countries also have projects for building $10 \mathrm{MW}$ solar power stations, while in Japan, Mitsubishi Heavy Industries has announced a plan for a $1000 \mathrm{MW}$ solar power station.

Whichever of the two methods is envisaged for the future, however, the most difficult (and perhaps obvious) problem is yet to be resolved: how to store the energy produced by solar power stations, for they can only function when the weather is clear and sunny. In the photovoltaic system, electrochemical storage is expensive; with thermodynamic power stations, on the other hand, one can more easily use thermal storage. Material costs, which have already been studied for nuclear programmes, would be relatively acceptable, and three materials are being considered: oils, rocks and dissolved salts. Great hopes are based also on the possibility of stock-piling hydrogen, obtained as a by-product in the photodissociation of water.

The USA has embarked on a very ambitious programme, with the objective of supplying $5-7 \%$ of its energy needs from solar energy in the year 2000 , and $25 \%$ in the year 2025. The Energy Research and Development Agency (ERDA) will assign $\$ 120$ million to the development of solar energy this year, and $\$ 160$ million in 1977 . France, coming second, has set aside for this year a sum of the same proportionate size relative to the GNP60-70 million francs, twice as much as in 1975. In comparison, Germany plans to spend only 36 million francs this year, and Japan slightly less.

\title{
INFLUENZA
}

\section{How it should work}

THE House Appropriations Committee has unanimously approved the $\$ 135$ million requested by President Ford to inoculate the American public against a possible epidemic of 'swine' influenza next winter. The first batches of vaccine against this new strain should be ready in midApril for clinical trials of its protective value.

If these are successful vaccination of those most at risk should begin in late summer. Representatives of the drug industry and government health officials testified before Congress this week that they hope to have the whole population inoculated by Christmas.

Rapid production of the vaccine can be achieved by an ingenious trick devised in the late 1960 s. A quickgrowing "master" strain of flu virus is hybridised with the swine flu to produce a recombinant bearing key characteristics of the swine flu virus. This recombinant can grow rapidly in fertilised hen's eggs, allowing vaccine production in 6-8 weeks rather than several months. The virus is then collected, killed and packaged into vaccine. It is reckoned that 50 to 100 million hen's eggs will be needed to produce the 200 million shots needed to vaccinate Americans. The protection expected with this vaccine will be between 70 and $80 \%$.

The $\$ 135$ million will cover the costs of production and distribution of vaccine only. Vaccination will be voluntary and those who can will have to pay for their flu shots, but
President Ford has stated that nobody will be denied vaccination if he cannot pay for it. The high-risk groups in the population will also automatically receive inoculation against the $\mathbf{A}$ and $\mathbf{B}$ strains which have been around this winter. But the emergency vaccine itself will only confer protection against the swine flu virus, which on its present showing in the one outbreak so far appears to produce generally less severe illness than the other strains prevalent this winter.

Meanwhile the Canadian government has also decided to approve a mass inoculation programme with swine flu vaccine. It plans to produce about 12 million doses, enough for about half the population, with preference to be given to high-risk groups. 